\title{
Molecular biomarkers of glioblastoma: current targets and clinical implications
}

This article was published in the following Dove Press journal:

Current Biomarker Findings

3 September 2012

Number of times this article has been viewed

\section{Koji Yoshimoto \\ Masahiro Mizoguchi \\ Nobuhiro Hata \\ Toshiyuki Amano \\ Akira Nakamizo \\ Tomio Sasaki}

Department of Neurosurgery, Graduate School of Medical Sciences, Kyushu University, Fukuoka, Japan
Correspondence: Koji Yoshimoto Department of Neurosurgery, Graduate School of Medical Sciences, Kyushu University, 3-I-I Maidashi, Higashi-Ku, Fukuoka 812-8582, Japan

Tel +8I 926425524

Fax +8I 926425526

Email kyoshimo@ns.med.kyushu-u.ac.jp
Abstract: Recent genome-wide analysis of glioblastoma has revealed various molecular alterations that can be candidate targets of biomarker findings. Although glioblastomas are diagnosed on the basis of their histopathological morphological features, it has been demonstrated that molecular heterogeneity among glioblastomas is prominent, and pathological diagnosis cannot always predict the clinical behavior of the tumor. Thus, molecular biomarkers have been anticipated to provide prognostic and predictive significance. Given that recent medical treatment strategies have been progressing toward individualized therapy and many targeted drugs have been investigated, the identification of molecular biomarkers in glioblastoma will be of considerable therapeutic importance. Although the clinical implications of these biomarkers must be determined in prospective studies, a growing number of candidate biomarkers have been investigated. In this review, the recent molecular alterations in glioblastoma that may be significant biomarkers are summarized; particular focus is on loss of heterozygosity on chromosome 10, epidermal growth factor receptor (EGFR)/EGFR variant III expression, alterations in the receptor tyrosine kinase-phosphatidylinositol 3-kinase pathway, isocitrate dehydrogenase mutation, epigenetic alterations, gene expression profiling, and microRNA expression.

Keywords: $E G F R v I I I, I D H$, global gene expression profiling

\section{Introduction}

Glioblastoma (GBM) is the most malignant neoplasm in adults. ${ }^{1-3}$ In recent years, many advancements have been made regarding treatment modalities for GBM patients. Fluorescence image-guided tumor removal with intraoperative neuro-functional monitoring increases the possibility of maximum tumor removal without neurological deficit, which prolongs patient survival. ${ }^{4,5}$ Recent radiotherapy modalities such as intensity-modulated radiation therapy and heavy charged particle therapy have been investigated to improve the treatment efficacy of conventional radiation therapy. 6,7 Moreover, temozolomide (TMZ), a new oral alkylating chemotherapeutic agent, has been demonstrated to enhance patient survival,, 8 and molecular targeted drugs such as epidermal growth factor receptor (EGFR) inhibitors and vascular endothelial growth factor receptor (VEGFR) antibodies have been used clinically. ${ }^{10}$ However, despite this technical advancement of therapeutic modalities, the treatment of patients with GBM has only improved minimally, with a median survival time of approximately 14 months, ${ }^{11,12}$ suggesting that effective therapeutic targets remain to be identified.

Recent molecular analysis has revealed characteristic molecular alterations in GBM that provide insight into its pathogenesis and tumor biology. ${ }^{13-19}$ Moreover, technological 
advancements of genome-wide genomic and transcriptional analysis have shifted the biomarker development from local analysis to global molecular alterations. Recently, The Cancer Genome Atlas (TCGA) project performed integrated genome-wide analysis of DNA copy number, DNA methylation aberrations, gene expression, and nucleotide sequence aberrations in 206 GBMs. ${ }^{20}$ This comprehensive analysis identified three critical signaling pathways in GBM - receptor tyrosine kinase (RTK)/Ras/phosphoinositide 3-kinase (PI3K) signaling, p53 signaling, and RB signaling indicating that the genomic alterations of these pathways are associated with the acquired characteristics of tumor cells. As Hanahan and Weinberg describe in their excellent review, cancer cells acquire biological capabilities not observed in their normal counterparts. ${ }^{21}$ The hallmarks of cancer cells include sustained proliferative signaling, resistance to growth suppression and cell death, replicative immortality, angiogenesis, and invasion and metastasis. In the most recent version, they added two emerging hallmarks to this original list, reprogramming energy metabolism and evading immune destruction, demonstrating that these hallmarks of cancer differentiate tumor cells from normal cells. Great efforts have been made in the cancer research field to identify meaningful molecular biomarkers from these molecular characteristics of cancer cells.

According to Biomarkers Definitions Working Group, a biomarker is defined as "a characteristic that is objectively measured and evaluated as an indicator of normal biological processes, pathogenic processes, or pharmacological responses to a therapeutic intervention," 22 indicating that cancer biomarkers are functionally associated with the hallmarks of cancer. Biomarkers can be classified into diagnostic, prognostic, predictive, and pharmacodynamic subtypes. ${ }^{23}$ Diagnostic biomarkers are characteristic biochemical and functional characters specific to cancers, and prognostic biomarkers can identify the patient groups with better clinical outcomes. Predictive biomarkers can be utilized to identify the patient groups that will benefit from a particular treatment. Pharmacodynamic biomarkers can measure a treatment effect in tumor cells. Growing numbers of studies have identified candidate biomarkers in various cancers including GBM. ${ }^{17,24-30}$ For instance, chromosome 1p/19q codeletion is a prognostic and possible predictive biomarker of oligodendroglial tumors, ${ }^{24-26}$ and O6-methylguanine-DNA methyltransferase (MGMT) methylation is a prognostic and predictive biomarker following TMZ treatment in GBM. ${ }^{31}$ Because of the introduction of molecular targeted drugs and individualized therapy for GBM treatment, ${ }^{32-35}$ identification of meaningful molecular biomarkers is crucial for determining therapeutic strategy and predicting tumor recurrence. Moreover, a combination of biomarker genes has been reported to be more useful than a single biomarker. ${ }^{36}$ Although the significance of biomarkers must be validated in prospective studies, ${ }^{37}$ many candidate biomarkers of GBM have been published. In this review, some genetic, epigenetic, and transcriptional alterations that have been presumably designated as biomarkers in GBM are described as well as the emerging roles of cancer stem cell marker and microRNA (miRNA) expression.

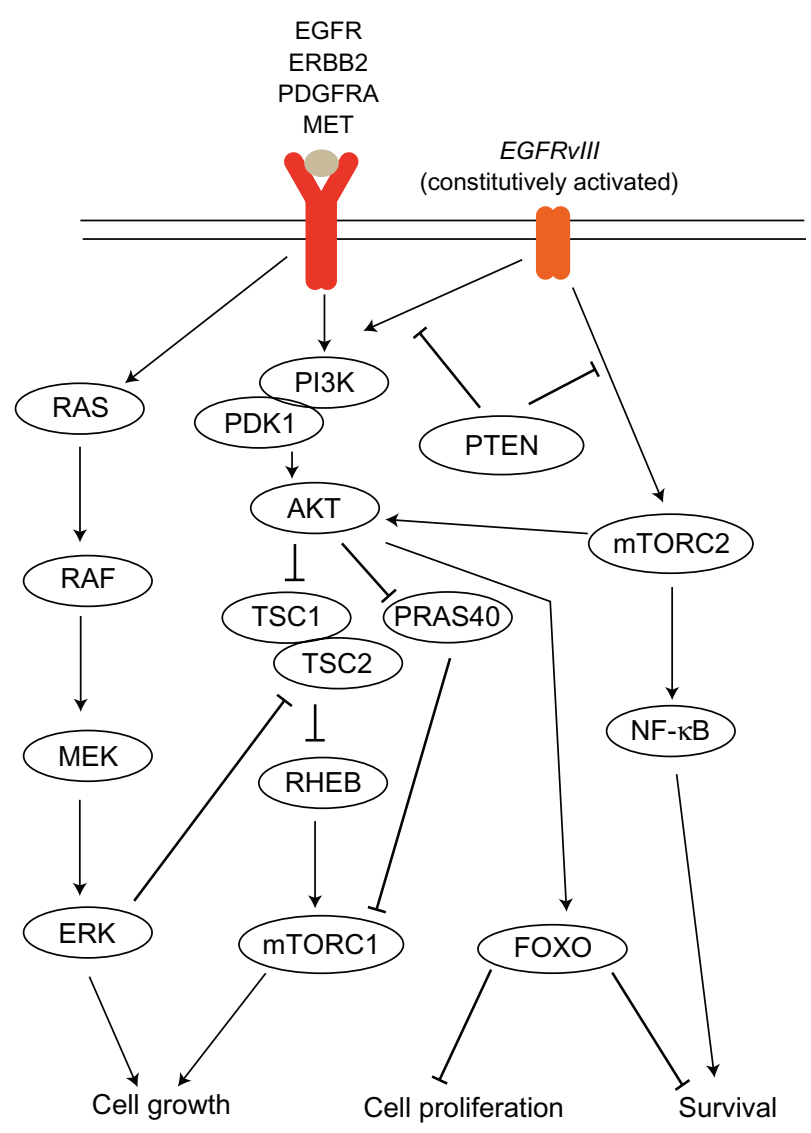

Figure I RTK-PI3K signaling pathway.

Notes: PI3K and RAS signaling is activated following ligand binding to EGFR and other RTKs such as ERBB2, PDGFRA, and MET. EGFRvIll signaling, which is constitutively activated without ligand binding, activates the mTORC2-NF- $\kappa B$ pathway independent of the PI3K-AKT pathway. Because PTEN suppresses PI3K and mTORC2 signaling, PTEN inactivation leads to the activation of these signaling pathways. AKT is activated following its phosphorylation by PDKI and mTORC2. AKT phosphorylation leads to the activation of $m$ TORCI via inhibition of negative regulators of TSCI, TSC2, RHEB, and PRAS40. In addition, AKT inhibits forkhead (FOXO) transcription factors, resulting in cell proliferation and survival.

Abbreviations: EGFR, epidermal growth factor receptor; EGFRvIII , EGFR variant III; mTORCI, mammalian target of rapamycin complex I; mTORC2, mammalian target of rapamycin complex 2; NF, nuclear factor; PI3K, phosphoinositide 3-kinase; PRAS40, proline-rich AKT substrate $40 \mathrm{KDa}$; PTEN, phosphatase and tensin homolog; RHEB, RAS homologue enriched in brain; RTK, receptor tyrosine kinase; TSCI, tuberous sclerosis complex I; TSC2, tuberous sclerosis complex 2. 


\section{Chromosome I 0 loss of heterozygosity (LOH)}

$\mathrm{LOH}$ is detected in many chromosomes in most common cancers. ${ }^{38,39}$ In GBM, LOH is frequently observed at chromosomes 9p, 10,17p, 19q, and $22,{ }^{16}$ but $\mathrm{LOH}$ at chromosome 10 is a critical genetic event. $\mathrm{LOH}$ can be routinely detected by polymerase chain reaction (PCR)-based polymorphic markers or fluorescence in-situ hybridization. Recently, genome-wide array-based technologies such as single nucleotide polymorphism-array analysis and comparative genomic analysis have been applied to detect copy number alterations. ${ }^{40,41}$ Three commonly deleted loci have been identified thus far: 10p14-15, 10q23-24, and 10q25-pter. ${ }^{42,43}$ Although LOH at 10p is also observed in low-grade glioma ${ }^{44}$ and it is a rare event in secondary GBM, LOH at $10 p$ and $10 \mathrm{q}$ regions has been reported in $60 \%-80 \%$ of cases of GBM, and these events can be genetic markers for both primary and secondary GBM. ${ }^{42,43,45,46}$ In particular, LOH at 10q 25-pter is associated with acquisition of the GBM phenotype in secondary GBM. ${ }^{42}$ By contrast, LOH at chromosome 10 is more extensive in primary GBM, ${ }^{43}$ and the loss of an entire chromosome is common, suggesting that $\mathrm{LOH}$ of the entire chromosome 10 can be a molecular marker of primary GBM.
As the occurrence of specific frequent deletions is considered to indicate the presence of tumor suppressor genes implicated in tumor initiation and progression based on Knudson's twohit theory, great efforts have been made to discover tumor suppressor genes on LOH loci. However, only phosphatase and tensin homolog (PTEN) has been identified in the 10q23 region as a critical tumor suppressor. ${ }^{47,48}$ However, the mutation frequency is $15 \%-40 \%,{ }^{49,50}$ indicating the presence of other unidentified tumor suppressors. Nevertheless, LOH at chromosome 10q is a prognostic biomarker because GBM patients with $10 \mathrm{q}$ loss have a significantly shorter survival than patients who retain chromosome $10.45,51$ Although LOH of chromosome regions is normally attributable to deletion of one allele with copy number loss, it has been demonstrated that copy number-neutral LOH occurs frequently in GBM, indicating that this type of $\mathrm{LOH}$ can result from mitotic recombination or nondisjunction. ${ }^{52}$

\section{EGFR/EGFR variant III (EGFRvIII )}

In GBM, the EGFR gene, which is located at chromosome 7, is amplified in $40 \%-50 \%$ of cases of GBM. ${ }^{20,53-55} \mathrm{~A}$ recent statistical analysis of genomic alterations by Beroukhim et al demonstrated that there are two types of genomic

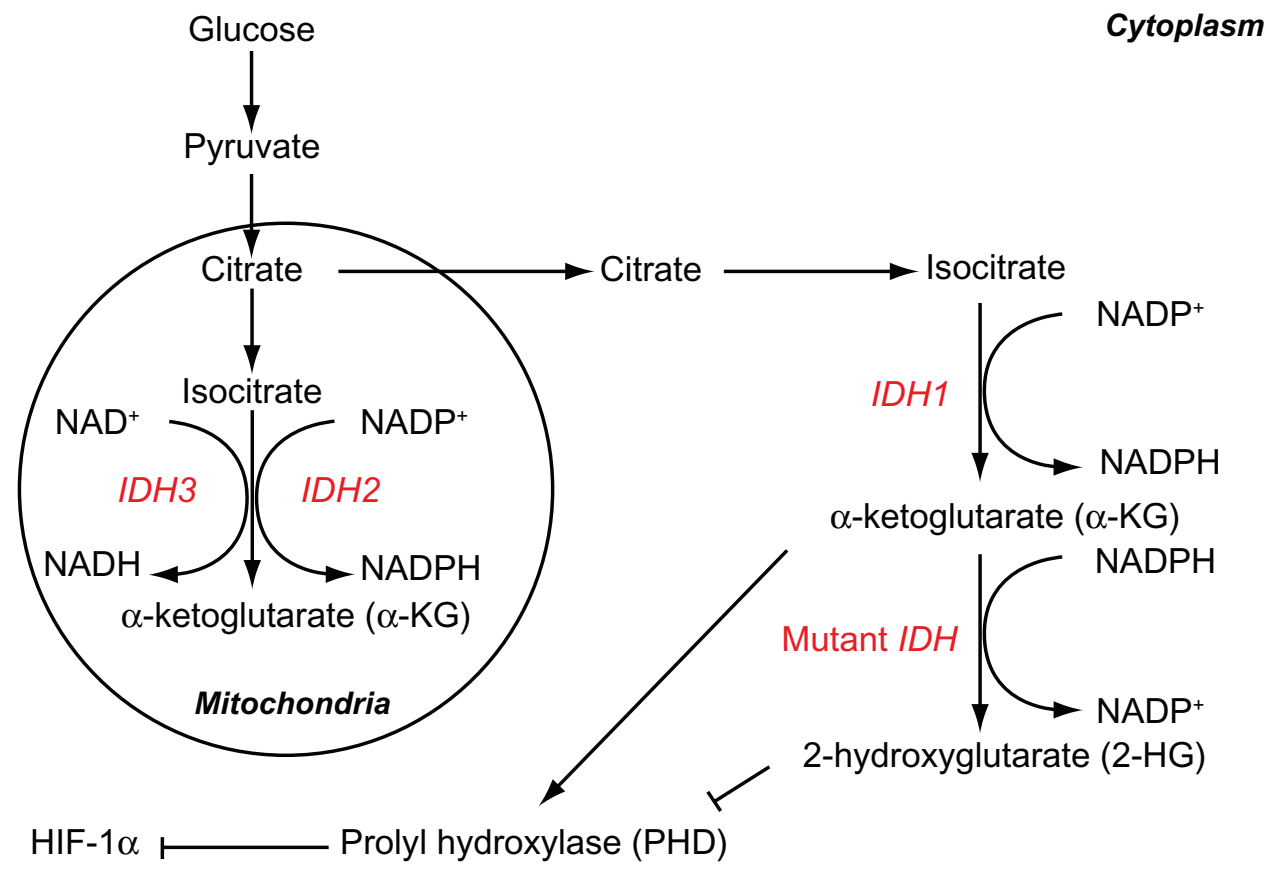

Figure 2 The role of IDH and IDH mutations in cellular metabolism.

Notes: IDHI is located in the cytoplasm, whereas IDH2 and IDH3 are located in mitochondria. IDH3 converts NAD ${ }^{+}$into $\mathrm{NADH}$. Wild-type IDHI converts NADP+ into $\mathrm{NADPH}$, which generates $\alpha-K G$ from isocitrate. Mutant IDHI protein produces $2-\mathrm{HG}$ from $\alpha-\mathrm{KG}$, thus mediating the formation of heterodimers between 2-HG and $\alpha-\mathrm{KG}$, which inhibit the activities of $\alpha$-KG-dependent PHD. The suppression of PHD leads to the increased expression of HIF-I.

Abbreviations: HG, hydroxyglutarate; HIF, hypoxia inducible factor; IDH, isocitrate dehydrogenase; KG, ketoglutarate; $\mathrm{NAD}^{+}$, nicotinamide adenine dinucleotide; PHD, prolyl hydroxylase. 


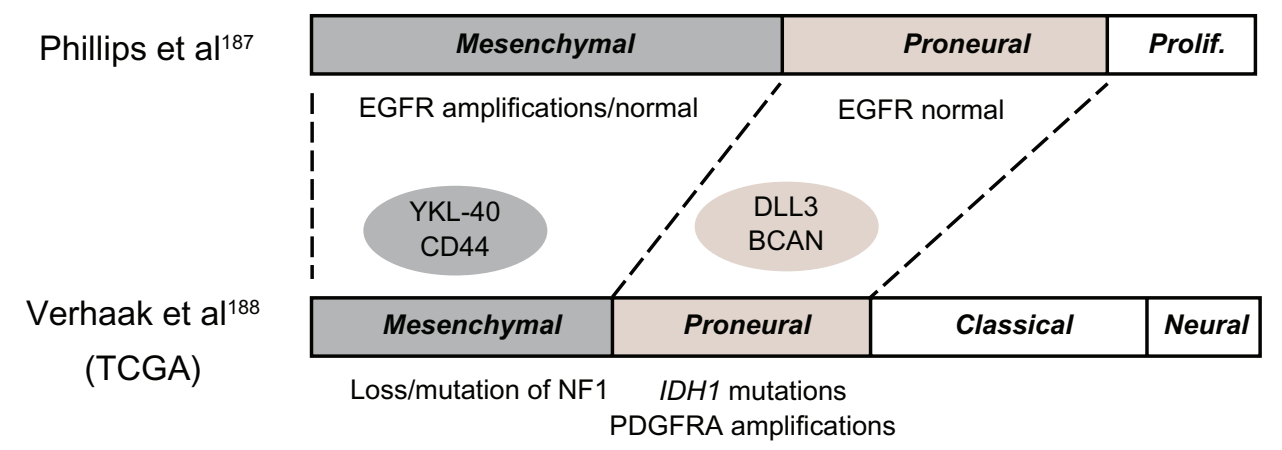

Figure 3 Transcriptional subtypes of glioblastoma.

Notes: Mesenchymal and proneural subtypes are concordant between the study by Phillips et al ${ }^{187}$ and that by Verhaak et al. ${ }^{188}$ In the Phillips et al study, EGFR amplification was frequently associated with the mesenchymal subtype, whereas the EGFR locus was likely to be normal in the proneural group. The Verhaak et al study showed that the mesenchymal subtype is associated with loss/mutation of NFI and IDHI mutation, and proneural subtype is associated with PDGFRA amplification.

Abbreviations: EGFR, epidermal growth factor receptor; IDH, isocitrate dehydrogenase; NF, nuclear factor; TCGA, The Cancer Genome Atlas.

amplification of chromosome 7 - focal high-level amplification at the EGFR gene, which is associated with EGFR activation, and broad low-level amplification of the entire chromosome, which often activates another receptor tyrosine kinase, MET - suggesting that the functional significance of EGFR amplification needs to be determined in the context of the level of amplification. ${ }^{40}$ EGFR amplification is often associated with truncated mutations, and EGFRvIII is the most common mutant. ${ }^{56}$ EGFRvIII is detected in $50 \%-60 \%$ of cases of GBM with amplified wild-type EGFR, and this mutant has deletions of exon $2-7$, lacking a portion of the extracellular ligand binding domain, thus constitutively activating downstream pathways without ligand binding. ${ }^{57,58}$ Activating signaling pathway via wild-type EGFR overexpression can be differentiated from EGFR-non-overexpressing tumors, and EGFR-amplified tumors have a worse prognosis than nonamplified tumors. ${ }^{59}$ However, EGFRvIII expression has been demonstrated to confer a worse prognosis than EGFR wild-type expression alone. ${ }^{60,61}$ Transfection of the EGFRvIII mutant into GBM cell lines enhances tumorigenicity in vivo due to increased proliferation and reduced apoptosis. ${ }^{62,63}$ Furthermore, it has been demonstrated that the expression of the constitutive mutant form of EGFRvIII in glial or neural cells can induce GBM formation in mice via interactions with another signaling pathway, and the genetic characterization of the formed tumors recapitulated human GBM. ${ }^{64,65}$ Although the downstream pathways activated by EGFRvIII have not been completely elucidated, EGFRvIII is constitutively phosphorylated, thus resulting in stronger PI-3K (discussed in the next section) activation than wild-type EGFR signaling. ${ }^{66,67}$ Moreover, it has been reported that EGFRvIII confers enhanced tumorigenicity and therapeutic resistance through the Ras-Shc-Grb2, interleukin-8, and mammalian target of rapamycin (mTOR) complex 2 (mTORC2)-nuclear factor (NF)- $\mathrm{kB}$ pathways. ${ }^{68-70}$ These results indicate that EGFRvIII uses different downstream signals from wildtype EGFR, suggesting that this variant can be a molecular target for individualized therapy. Indeed, it has been reported that mutant EGFRvIII expression can be a molecular predictor of a better response to EGFR kinase inhibitor therapy in GBM..$^{71}$ In addition, Montano et al recently demonstrated that EGFRvIII is a molecular predictor of longer overall survival in GBM patients treated with surgery followed by adjuvant radiotherapy and TMZ in contrast to earlier studies in which EGFRvIII was a biomarker of a poorer prognosis. ${ }^{72}$ This discrepancy may be partially explained by the fact that Montano et al used a reversetranscription PCR assay on selected regions of formalinfixed, paraffin-embedded tumor specimens, which is a more sensitive method for detecting EGFRvIII expression than conventional immunohistochemistry. More importantly, the patient population in the Montano study was uniform in that all patients underwent surgery followed by concomitant radiation and TMZ therapy, which is the consensus standard therapy that was introduced recently in the clinic, indicating that the biological significance of EGFRvIII expression should be explored in the context of therapeutic modalities. Furthermore, Bredel et al recently identified a subset of GBM that harbors monoallelic loss of NFKBIA, which encodes $\mathrm{I} \kappa \mathrm{B}$, a critical negative regulator of the canonical NF- $\mathrm{KB}$ pathway, and NFKBIA deletion and EGFR amplification are mutually exclusive. This study also implied a functional relationship between EGFR and NF- $\kappa \mathrm{B}$ signaling and potential therapeutic targets. ${ }^{73}$

Given that EGFRvIII expression is not found in any normal tissues and it is a constitutively active cell surface protein, EGFRvIII can also be a target for peptide vaccination immu- 
notherapy. ${ }^{74,75}$ The recent data of a Phase II multicenter clinical trial revealed that EGFR $I I I$-targeted vaccination therapy is a promising therapy for patients with GBM. ${ }^{76}$ Regarding EGFR-targeted therapy, GBM patients respond poorly to EGFR kinase inhibitors such as gefitinib and erlotinib in contrast to lung cancer patients with EGFR kinase domain mutations. ${ }^{77}$ Recently, novel oncogenic missense mutations in the extracellular domain and carboxyl-terminal deletion mutants have been reported, and these specific mutants selectively respond to EGFR kinase inhibitors. ${ }^{78-80}$ These results imply that similar to the observations in lung cancer, EGFR-specific mutations are associated with a good response to EGFR kinase inhibitors in GBM. Further studies are mandatory to address this issue.

\section{RTK/PI3K pathway}

As has been reported in various studies, the PI3K-AKT pathway is frequently activated in GBM, indicating that it can be a molecular target. ${ }^{81-83}$ Indeed, many newly developed drugs targeting the PI3K pathway have been investigated in clinical trials for various types of cancers, including GBM. ${ }^{84}$ This pathway is known to be activated through several mechanisms, including RTK amplifications, and mutations including EGFR as described previously (Figure 1). The PI3K complex consists of a catalytically active protein, p110a, encoded by PIK3CA, and a regulatory protein, p85a, encoded by PIK3R1. Frequent active mutations of PIK3CA in GBM have been reported, ${ }^{85}$ and TCGA analysis revealed somatic mutations in PIK3R1, ${ }^{20}$ indicating that PIK3CA and PIK3R1 mutations are mechanisms of PI3K pathway activations. However, AKT1 mutations have been reported to be absent in GBM. ${ }^{86}$ PTEN, which maps to chromosome $10 \mathrm{q} 23$, has been identified as a tumor suppressor gene in GBM. ${ }^{47,48}$ PTEN is a negative regulator of the PI3K pathway, and inactivation of PTEN via genetic loss, mutation, and epigenetic mechanism occurs in $30 \%-40 \%$ of cases of GBM. This inactivation leads to PI3K pathway activation. ${ }^{87}$ It has been reported that PTEN inactivation confers resistance to EGFR kinase inhibitors in patients harboring EGFRvIII mutations by activating the downstream AKT pathway and increasing EGFR activity by impairing degradation. ${ }^{71,88}$ In addition to its function as a regulator of cell proliferation and migration through lipid phosphatase function, PTEN is reported to be a key player in the DNA damage response and stem cell maintenance. Although PTEN protein has been assumed to be localized in the cytoplasm, growing amounts of evidence indicate that PTEN is primarily localized in the nucleus in differentiated and resting cells, and its predominant expression is shifted to the cytoplasm in cancer cells, thereby suggesting that PTEN can translocate from the nucleus to the cytoplasm. ${ }^{89}$ It has been also revealed that nuclear PTEN plays an essential role in maintaining chromosome integrity, partly through regulating double-strand break repair pathways. ${ }^{90}$ Moreover, Li et al revealed that PTEN loss and EGFRvIII synergistically transform neural precursor cells by inducing chromosome instability, ${ }^{91}$ and McEllin et al have demonstrated that PTEN loss compromises the homologous recombination repair pathway in astrocytes. ${ }^{92}$ These results demonstrate that lipid phosphatase-independent roles of PTEN also have an important role in gliomagenesis.

mTOR is another molecular target of the PI3K pathway. mTOR exists in 2 distinctive complexes with other molecules. ${ }^{93}$ mTOR complex 1 (mTORC1) forms a complex with regulatory associated protein of mTOR (Raptor) and mLST8 and is an important downstream effector of the PI3K pathway, acting as a signal integrator of nutrients, growth factors, and energy and stress inputs to involve the processes of protein and lipid biosynthesis and cellular metabolism. ${ }^{94}$ This indicates that mTORC1 can be a therapeutic target of rapamycin and its derivatives. However, it has been demonstrated that single mTOR inhibitor therapy does not have significant efficacy in GBM patients due to the activation of a negative-feedback AKT pathway, suggesting a rationale for combination therapy with $\mathrm{mTOR}$ inhibitors and PI3K inhibitors. ${ }^{95}$ In contrast to mTOR1, the roles of rapamycin-insensitive mTORC2 have been elusive. Recently, Tanaka et al demonstrated that EGFRvIII signaling activates the mTORC2-NF- $\mathrm{KB}$ pathway, indicating a critical role of mTORC2 in chemoresistance mechanisms independent of the AKT pathway. ${ }^{70}$ This study clearly demonstrated that both mTORC1 and mTORC2 play important roles in gliomagenesis and therapeutic resistance. Further studies have been undertaken to gain more insight into mTOR signaling in GBM.

\section{p53 and Rb pathways}

The tumor suppressor TP53 is a key molecule that plays critical roles in various biological processes such as the cell cycle, DNA damage response, apoptosis, and cell differentiation. ${ }^{96,97}$ The function of p53 is negatively regulated by MDM2 and MDM4, the expressions of which are subject to negative regulation by ARF. This p53/MDM2/4/ARF signaling is altered in $87 \%$ of TCGA cases. ${ }^{20}$ TP53 mutation is detected in $31 \%-35 \%$ of all GBM, although TP53 mutation is more frequently observed in secondary GBM $(65 \%)$ than in primary GBM (28\%). ${ }^{20,98}$ Amplification of MDM2 
is detected in approximately $10 \%$ of GBM exclusively, without TP53 mutation..$^{20,98,99}$ Loss of ARF expression, which can be induced by homologous deletion, mutation, and promoter methylation, has been observed at a frequency of $49 \%-76 \%$ in GBM. ${ }^{15,20}$ Regarding the prognostic significance of the TP53 signaling pathway, TP53 status has been reported to be neither a prognostic nor a predictive biomarker in GBM. ${ }^{24,100}$ However, owing to the crucial role of the p53 signaling pathway in numerous cancers including GBM, ${ }^{13,14}$ efforts have been made to develop therapeutic strategies that target the p53 pathway by reactivating p53 signaling with peptides and small molecules. ${ }^{101,102}$

The retinoblastoma $(R B)$ gene is a negative regulator of cell cycle progression from $\mathrm{G} 1$ to $\mathrm{S}$ phase. ${ }^{13,14}$ Inactivation of the $R B$ gene by homologous deletion and mutation is observed at a frequency of $11 \%{ }^{20}$ The rate of methylation of the promoter region in the $R B 1$ gene has been reported to be $25 \%{ }^{103}$ The $R B$ gene signaling pathway is altered in $78 \%$ of GBM cases $^{20}$ owing to the amplification of cyclin-dependent kinase 4 (CDK4) and loss of p16INK4A, as well as altered expression of the $R B 1$ gene. Although the importance of the inactivation of the RB pathway in glioma progression has been demonstrated, the prognostic significance of alterations in the RB pathway is controversial. ${ }^{100,104}$

\section{Isocitrate dehydrogenase (IDH) mutation}

Genome-wide mutational analysis disclosed recurrent mutations in the active sites of the $I D H 1$ or 2 gene in GBM at a frequency of $12 \%(18 / 149) .{ }^{105}$ The most common sites of mutations in $I D H 1$ and $I D H 2$ are codons R132 and R172, respectively. Secondary GBM has a remarkably high frequency of $I D H$ mutations compared with primary GBM (5/6 versus 7/99), and patients with $I D H$ mutations have a significantly improved prognosis. Subsequent analysis of a large set of glioma samples with different histologies and grades has also demonstrated that $I D H$ mutations occurred in $70 \%-100 \%$ of World Health Organization-grade II-III astrocytic tumors, oligodendroglial tumors, and secondary GBM, whereas primary adult GBM exhibited a low frequency of this mutation (4.9\%). ${ }^{106-108}$ These results implicate a role of $I D H$ mutations in gliomagenesis, and these mutations are associated with the malignant progression of gliomas. The low frequency of mutation in primary GBM indicates the presence of $I D H$-dependent and $I D H$-independent pathways of glioma development.

IDH1 is localized in the cytoplasm and peroxisomes, whereas $I D H 2$ and $I D H 3$ are localized in the mitochondria, where they participate in the citric acid cycle for energy production. ${ }^{109-111}$ Wild-type $I D H 1$ and $I D H 2$ function as $\mathrm{NADP}^{+}$-dependent $I D H$ s that catalyze the oxidative decarboxylation of isocitrate to $\alpha$-ketoglutarate $(\alpha-\mathrm{KG})$, generating NADPH from $\mathrm{NADP}^{+}$(Figure 2). In normal cells, mitochondrial NADPH is of fundamental importance in the defense against reactive oxygen species (ROS), regulating NADPH-dependent glutathione reductase. Different from the wild-type proteins, mutant $I D H 1$ and $I D H 2$ proteins display the novel enzymatic property of producing 2-hydroxyglutarate $(2-\mathrm{HG})$ from $\alpha-\mathrm{KG}$, facilitating heterodimer formation between $2-\mathrm{HG}$ and $\alpha-K G .{ }^{112-114}$ The dominant-negative effect of $2-\mathrm{HG}$ and the reduction of $\alpha-\mathrm{KG}$ inhibit the activities of $\alpha-\mathrm{KG}$-dependent dioxygenase family proteins (prolyl hydroxylase) that catalyze the hydroxylation of hypoxia inducible factor (HIF) to cause its degradation. Thus, $\alpha-\mathrm{KG}$ downregulation increases the levels of HIF-1 $\alpha$, a transcription factor that facilitates tumor growth when oxygen is low. ${ }^{115} I D H$ is the first metabolic enzyme for which genetic and biochemical alterations have been incorporated into the basics of cancer biology. Given that tumors with $I D H 1$ and IDH2 mutations have highly elevated (10-100-fold) levels of 2-HG, 2-HG can be used as an important biomarker of tumors with $I D H 1 / 2$ mutations. ${ }^{112,113}$ Choi et al recently reported that $2-\mathrm{HG}$ can be detected using magnet resonance spectroscopy (MRS) in IDH-mutated gliomas, suggesting that the noninvasive detection of 2-HG may prove to be a valuable diagnostic biomarker. ${ }^{116}$

An emerging role of $I D H 1$ and IDH2 mutations is their association with the hypermethylation phenotype (discussed in the next section) in tumor cells. In leukemia cells, mutant IDH1 and IDH2 disrupt the function of TET2, a DNA demethylase enzyme, causing DNA hypermethylation and impairing differentiation in hematopoietic cells. ${ }^{117}$ Although genomic mutation of TET2 is not evident in glioma, IDH mutations are significantly associated with a methylator phenotype (glioma-CpG island methylator phenotype [G-CIMP] phenotype) in GBM. ${ }^{118}$ The functional correlation between $I D H$ mutations and the G-CIMP phenotype was verified by the recent study by Turcan et al, who demonstrated that $I D H$ mutation is the cause of the G-CIMP phenotype through an epigenomic reprogramming mechanism. ${ }^{119}$ A subsequent study demonstrated that $I D H$ mutations are associated with dysregulation of glial differentiation and global histone methylation in low-grade gliomas, and 2-HG can inhibit histone demethylation, blocking the differentiation of nontransformed cells. ${ }^{120}$ These results indicate that $I D H$ mutants have a wide variety of biological functions. 
Along with their functional significance, $I D H$ mutations are prognostic biomarkers in glioma patients. It has been revealed that patients with $I D H 1 / 2$ mutations have a significantly better outcome than those with wild-type $I D H$ in GBMs, anaplastic astrocytomas, and anaplastic oligodendroglial tumors. ${ }^{105-107,121,122}$ Although the difference is not significant, patients with diffuse astrocytoma with IDH1/2 mutations tend to have a longer survival than those with wild-type $I D H \cdot{ }^{123}$ As specific mutant antibodies against R132 IDH1 and R176 IDH2 are available in the clinical setting, immunohistochemical detection of $I D H$ mutations, as well as neuroradiological detection by MRS as described above, can facilitate patient stratification for selecting patients with a better prognosis. Great efforts have been made toward developing targeted therapies for mutant $I D H 1$ and $I D H 2$ that modify their enzymatic activity. However, these targeted therapies have potential effect only for a small subset of primary GBM because pathway activation in most primary GBM subtypes is $I D H$ independent.

\section{Epigenetic alterations}

"An epigenetic trait is a stably heritable phenotype resulting from changes in a chromosome without alterations in the DNA sequence;" this results in variable gene expression. Epigenetic modifications in cancer are characterized by global changes in DNA methylation and altered histone modifications. ${ }^{124-126}$ Emerging roles of epigenetic alterations in glioma biology have been recently reported. ${ }^{27,28,118,127-129}$ DNA methylation occurs at the $5^{\prime}$ position of the cytosine ring within $\mathrm{CpG}$ dinucleotides, resulting in gene silencing. DNMT1 is the DNA methyltransferase that maintains existing methylation during DNA replication, whereas DNMT3A and DNMT3B are responsible for methylating previously unmethylated regions. In cancer cells, epigenetic alterations of DNA methylation are present with global DNA hypomethylation and hypermethylation of locus-specific promoters within $\mathrm{CpG}$ islands. In GBM, it was reported that global hypomethylation associated with genome-wide reduction of 5-methylcytosine was detected in 8 of 10 primary GBM tissues, and the extent of 5-methylcytosine reduction was at least $60 \%-70 \%$ with more severe reduction to less than $50 \%$ in two cases. ${ }^{130}$ DNA hypomethylation mainly occurs at repetitive DNA sequences, generating chromosome rearrangement, reactivation of transposable elements, and loss of imprinting. ${ }^{131}$ Indeed, Fanelli et al demonstrated that demethylation of repetitive sequences such as tandem repeat satellite 2 located at the juxacentromeric region of chromosome 1 could contribute to genomic instability in human GBM. ${ }^{132}$ Furthermore, loss of imprinting of insulinlike growth factor-2 is present in more than half of gliomas, suggesting a critical role of this protein in the development of glioma. ${ }^{133}$

Locus-specific hypermethylation of $\mathrm{CpG}$ islands in the promoter region is associated with the maintenance of tumor suppressor gene silencing as well as other various functions such as cell cycle regulation, DNA repair, angiogenesis, and invasion. $\mathrm{CpG}$ islands in the promoters of tumor suppressor p53, PTEN, RB, CDKN2/p16, and P14ARF are frequently methylated in GBM, indicating that their tumor suppressive function is inhibited. ${ }^{127,129}$ In addition, the DNA repair protein MGMT is frequently methylated in the promoter regions. MGMT removes TMZ-generated O6-methylguanine DNA adducts by transferring the methyl adducts to its own cysteine residues, indicating that MGMT activity is associated with the therapeutic response to TMZ. ${ }^{134-136}$ As promoter methylation is likely to be associated with MGMT gene silencing, ${ }^{137,138}$ the potential utility of promoter methylation of MGMT as a predictive biomarker for TMZ chemotherapy has been investigated. Consequently, it was demonstrated that MGMT methylation is associated with a better clinical response to TMZ and concomitant radiotherapy in GMB than wild-type MGMT. ${ }^{11,31,139,140}$ However, this notion was challenged by the finding that MGMT inactivation was associated with a better response to radiation therapy alone, suggesting that the functional significance of MGMT methylation needs to be revalidated in future studies. ${ }^{141}$ Additionally, Kreth et al demonstrated that the MGMT mRNA expression level is not consistent with the degree of promoter methylation in $20 \%$ of cases of GBM, and mRNA expression is a better predictor of the efficacy of concomitant radio-chemotherapy than MGMT methylation. ${ }^{142}$ Although it has not been completely determined whether promoter methylation, mRNA expression, or the protein level best predict the therapeutic response, MGMT gene silencing is associated with chemotherapeutic resistance, but it is not the only predictor. ${ }^{143}$ Recently, it was reported that the base excision repair enzyme alkylpurine-DNA- $N$-glycosylase (APNG), which repairs the major cytotoxic lesions N3-methyladenine and N7-methylguanine, confers TMZ resistance independent of MGMT methylation, and APNG expression is also regulated by promoter methylation. ${ }^{144}$ Collectively, these results indicate that $\mathrm{CpG}$ island hypermethylation in DNA repair genes can be a biomarker in GBM.

A CIMP was first characterized in subsets of colon cancer tumors. ${ }^{145}$ TCGA group recently reported that a subset of GBM displays hypermethylation of a large number of loci, a 
characteristic called a G-CIMP. ${ }^{118}$ G-CIMP defines a distinct subgroup of gliomas that belong to the proneural type (described in the next section) and that are tightly associated with IDH mutations. Thus, it is possible that G-CIMP status can stratify the patients with different molecular features and clinical responses to therapeutic interventions.

Gene expression is regulated by histone modifications such as acetylation, methylation, phosphorylation, sumoylation, and ubiquitination. ${ }^{124-126}$ Histones are small proteins with a high proportion of positively charged amino acids (lysine and arginine) consisting of two molecules each of $\mathrm{H} 2 \mathrm{~A}, \mathrm{H} 2 \mathrm{~B}, \mathrm{H} 3$, and H4. Because histone acetylation neutralizes the positive charge of lysine residues and weakens the binding between DNA sequences, histone acetylation is linked to transcriptional activation. Meanwhile, histone methylation mainly occurs on the side chains of lysine and arginine, and it activates ( $\mathrm{H} 3 \mathrm{~K} 4 \mathrm{me} 2, \mathrm{H} 3 \mathrm{~K} 4 \mathrm{me} 3)$ or represses (H3K9me2, H3K27me3) transcription depending on which site is methylated. Histone deacetylase (HDAC) catalyzes the deacetylation of lysine residues, resulting in transcriptional repression. Given that HDAC is overexpressed in cancer cells, HDAC inhibitors (HDACi) have been tested for clinical utility in GBM. ${ }^{127,128}$ The basic mechanism of HDACi therapy in cancer treatment is that they relax the chromatin structure, thus allowing access of DNA damaging agents to chromatin, which results in the reversal of epigenetic tumor suppressive gene silencing. Although several classes of HDACi compounds are available, such as hydroxamates (SAHA, TSA) and aliphatic acids (valproic acid), no single agent is effective against GBM thus far. The clinical implication of histone modification and the utility of therapeutic targets should be evaluated in future research.

\section{Stem cell marker expression}

Recent cancer stem cell biology findings advocate that rare populations of cancer stem cells define therapeutic response to chemo-radiotherapy, and they can be a source of tumor recurrence. ${ }^{146-149}$ Glioma stem cells have been identified and propagated from tumor cell populations, ${ }^{150,151}$ and the glioma stem cell paradigm has been reviewed in many articles. ${ }^{152-157}$ It has been demonstrated that glioma stem cells exhibit therapeutic resistance to chemo-radiotherapy, ${ }^{158-160}$ indicating that glioma stem cells can be therapeutic targets. ${ }^{161-163}$ Because glioma stem cells are known to express neural stem cell markers, ${ }^{164-166}$ these markers can be used to isolate tumor cells with stem cell properties. In addition, the expression of some stem cell markers such as CD133,
Nestin, BMI-1, MELK, and Notch in GBM tissue has been reported to have prognostic significance in GBM. ${ }^{167-173}$ However, it should be remembered that the stem cell marker expression of tumor cells does not indicate its stem cell potential. Moreover, increasing amounts of evidence have revealed that the therapeutic resistance of glioma stem cells is defined by both the inherent features of glioma stem cells and close interaction with the tumor microenvironment, suggesting that the functional significance of glioma stem cells should be discussed in the context of the tumor microenvironment. ${ }^{174-178}$

\section{Global gene expression profiling}

Recent technological advancements in genome-wide expression profiling have demonstrated that the molecular stratification of GBM provides better prognostic information than traditional histopathological classification, suggesting that this type of molecular subclassification can be a better classifier in terms of clinical implications. ${ }^{179-183}$ Thus, many attempts have been made to identify biomarkers using global expression profiling. ${ }^{184}$ Although the statistical variability of global expression data is of concern in some situations, ${ }^{185,186}$ several clinically relevant subclassifications have been advocated. Phillips et al identified three GBM subtypes (proneural, proliferative, and mesenchymal) based on the expression profiles of genes correlated with patient survival. ${ }^{187}$ The proneural subtype exhibits high expression of genes implicated in neurogenesis and those associated with better clinical outcomes. By contrast, the proliferative and mesenchymal subtypes are characterized by the high expression of genes correlated with cell proliferation and angiogenesis, respectively, and both subtypes are associated with poor clinical outcomes. Verhaak et al classified TCGA GBM samples into four subtypes (proneural, neural, mesenchymal, and classical) via consensus clustering of genome-wide expression profiles. ${ }^{188}$ In this subclassification scheme, aberrations and the gene expression of EGFR, NF1, and PDGFRA/IDH1 each define the classical, mesenchymal, and proneural subtype, respectively. However, no prognostic differences were observed among the four different subtypes. Although the classification schemes by Phillips et al ${ }^{187}$ and Verhaak et $\mathrm{a}^{188}$ used different sample sets and methodologies, Huse et al ${ }^{189}$ used cross-validation analysis to reveal that the proneural and mesenchymal signatures are concordant between the two studies, suggesting that these two subcategories are robust (Figure 3). The proneural subtype displays frequent associations with the G-CIMP phenotype 
and secondary GBM, whereas the mesenchymal subtype is exclusively detected in primary GBM. In addition, it has been demonstrated that tumors tend to shift toward mesenchymal signaling upon recurrence. Therefore, the mesenchymal signaling pathway can be a therapeutic target. YKL-40 has been designated as a representative mesenchymal marker. ${ }^{187,188}$ Carro et al identified two transcriptional factors, $\mathrm{C} / \mathrm{EBP} \beta$ and STAT3, as initiators and master regulators of mesenchymal transformation. ${ }^{190}$ Furthermore, Bhat et al revealed that transcriptional coactivator with PDZ-binding motif (TAZ) regulates mesenchymal differentiation in glioma. ${ }^{191}$ Although many other signaling molecules implicated in this pathway remain to be identified, it is possible that inhibiting these key signaling molecules can have a tumor-suppressive effect. In addition, Prins et al reported that mesenchymal gene signatures may identify an immunogenic subgroup of GBM that may be more responsive to dendritic immunotherapy, ${ }^{192}$ suggesting that the mesenchymal signature can be a predictive molecular marker for several therapeutic modalities.

\section{miRNA expression}

miRNAs are 21-nucleotide small, noncoding RNA molecules that regulate the expression of a wide variety of genes at the post-transcriptional level. ${ }^{193-195}$ Emerging evidence indicates that miRNAs can function as negative gene regulators in normal tissues and as tumor suppressors and oncogenes in various cancers. ${ }^{196-198}$ MiR-21 is a highly expressed miRNA in cancers including GBM, and it acts as an oncogene to inhibit apoptosis in GBM cells. ${ }^{199,200}$ Several other miRNAs have been validated as having functional significance in GBM biology, including miR-7, miR-34a, miR-124, miR-137, and miR-128. ${ }^{201-205}$ Recently reported is that miR-196 might play an important role in the malignant progression of GBM and have prognostic significance. ${ }^{206}$ Given that miRNAs have the potential to regulate the expression of a large number of genes, growing evidence indicates that miRNA expression profiles are better classifiers than messenger RNA-based classification in terms of clinical implications in cancer patients. ${ }^{207}$ Srinivasan et al recently demonstrated that a 10-miRNA expression signature predicts patient survival in GBM patients. ${ }^{208} \mathrm{Kim}$ et al performed consensus clustering of GBM samples using miRNA expression profiles and identified five clinically and genetically distinct subclasses of GBM that are related to a different precursor cell type with robust survival difference. ${ }^{209}$ These results indicate that miRNAs are useful for subclassifying GBMs and have potential utility as molecular biomarkers.

\section{Future perspectives}

Although the current status of molecular biomarkers has been discussed by focusing on DNA, mRNA, and miRNA in this review article, a growing number of studies have been published that describe the application of proteomics to biomarker discovery in glioma patients. ${ }^{210}$ Because biological fluids such as plasma/serum and cerebrospinal fluid are readily accessible sources for biomarker development, it can be confidently anticipated that many meaningful molecular biomarkers will be developed by less-invasive testing. Recently, the levels of serum YKL-40, a mesenchymal marker, were reported to be correlated with radiological disease status and patient survival in high-grade glioma, suggesting that serum YKL-40 is a prognostic and predictive molecular biomarker in GBM patients. ${ }^{211}$ In addition, recent evidence has revealed that tumor miRNA is secreted as circulating miRNA into body fluids, and this miRNA can be designated as a new potential biomarker for cancer diagnosis and prognosis. ${ }^{212,213}$

Exosomes (microvesicles) are membranous vesicles of 30-100 nm diameter that are released from many cell types into the extracellular space. A recent study showed that GBM tumor cells secreted exosomes that could be detected in the serum of patients. Moreover, these secreted exosomes contained tumor-specific mRNAs, miRNAs, and signaling proteins, indicating that tumor exosomes could be a potential source of novel biomarkers. ${ }^{214,215}$ Indeed, tumorspecific EGFRvIII was detected in serum exosomes in GBM patients, and the level of EGFRvIII correlated with tumor removal. ${ }^{214}$ Thus, exosomes are expected to be a biological source for biomarker development using serum drawn from GBM patients.

\section{Concluding remarks}

Numerous molecular features have been identified as candidate biomarkers of GBM. As cancer treatments including GBM have been moving toward individualized therapy, identifying predictive biomarkers is requisite for targeted therapy in GBM, and the clinical implications of these biomarkers should be critically evaluated. In addition, the clinical utility of a combination of multiple markers should be pursued. Furthermore, as stated previously, noninvasive biomarker findings in body fluids such as serum and cerebrospinal fluid have demonstrated promising results. ${ }^{211-215}$ It can be envisaged that new validated biomarkers of GBM will be used clinically to stratify patients and to derive prognostic and predictive information. 


\section{Acknowledgments}

This project was supported by grants 22390279 (K Yoshimoto) and 22390280 (M Mizoguchi) from the Ministry of Education, Culture, Sports, Science and Technology of Japan.

\section{Disclosure}

The authors report no conflicts of interest in this work.

\section{References}

1. Wrensch M, Minn Y, Chew T, Bondy M, Berger MS. Epidemiology of primary brain tumors: current concepts and review of the literature. Neuro Oncol. 2002;4(4):278-299.

2. Wen PY, Kesari S. Malignant gliomas in adults. N Engl J Med. 2008; 359(5):492-507.

3. Louis DN, Ohgaki H, Wiestler OD, et al. The 2007 WHO classification of tumours of the central nervous system. Acta Neuropathol. 2007; 114(2):97-109.

4. Stummer W, Pichlmeier U, Meinel T, Wiestler OD, Zanella F, Reulen HJ. Fluorescence-guided surgery with 5-aminolevulinic acid for resection of malignant glioma: a randomised controlled multicentre phase III trial. Lancet Oncol. 2006;7(5):392-401.

5. Sanai N, Berger MS. Operative techniques for gliomas and the value of extent of resection. Neurotherapeutics. 2009;6(3):478-486.

6. Mizoe JE, Tsujii H, Hasegawa A, et al. Phase I/II clinical trial of carbon ion radiotherapy for malignant gliomas: combined X-ray radiotherapy, chemotherapy, and carbon ion radiotherapy. Int J Radiat Oncol Biol Phys. 2007;69(2):390-396.

7. Sultanem K, Patrocinio H, Lambert C, et al. The use of hypofractionated intensity-modulated irradiation in the treatment of glioblastoma multiforme: preliminary results of a prospective trial. Int J Radiat Oncol Biol Phys. 2004;58(1):247-252.

8. Reardon DA, Rich JN, Friedman HS, Bigner DD. Recent advances in the treatment of malignant astrocytoma. J Clin Oncol. 2006;24(8): $1253-1265$

9. Stupp R, Hegi ME, van den Bent MJ, et al. Changing paradigms - an update on the multidisciplinary management of malignant glioma. Oncologist. 2006;11(2):165-180.

10. Wick W, Weller M, Weiler M, Batchelor T, Yung AW, Platten M. Pathway inhibition: emerging molecular targets for treating glioblastoma. Neuro Oncol. 2011;13(6):566-579.

11. Stupp R, Hegi ME, Mason WP, et al. Effects of radiotherapy with concomitant and adjuvant temozolomide versus radiotherapy alone on survival in glioblastoma in a randomised phase III study: 5-year analysis of the EORTC-NCIC trial. Lancet Oncol. 2009;10(5):459-466.

12. Stupp R, Mason WP, van den Bent MJ, et al. Radiotherapy plus concomitant and adjuvant temozolomide for glioblastoma. $N$ Engl $J$ Med. 2005;352(10):987-996.

13. Maher EA, Furnari FB, Bachoo RM, et al. Malignant glioma: genetics and biology of a grave matter. Genes Dev. 2001;15(11):1311-1333.

14. Furnari FB, Fenton T, Bachoo RM, et al. Malignant astrocytic glioma: genetics, biology, and paths to treatment. Genes Dev. 2007;21(21): 2683-2710.

15. Ohgaki H, Kleihues P. Genetic pathways to primary and secondary glioblastoma. Am J Pathol. 2007;170(5):1445-1453.

16. Ohgaki H, Kleihues P. Genetic alterations and signaling pathways in the evolution of gliomas. Cancer Sci. 2009;100(12):2235-2241.

17. Masui K, Cloughesy TF, Mischel PS. Molecular pathology in adult high-grade gliomas: from molecular diagnostics to target therapies. Neuropathol Appl Neurobiol. 2012;38(3):271-291.

18. Chen J, McKay RM, Parada LF. Malignant glioma: lessons from genomics, mouse models, and stem cells. Cell. 2012;149(1):36-47.

19. Dunn GP, Rinne ML, Wykosky J, et al. Emerging insights into the molecular and cellular basis of glioblastoma. Genes Dev. 2012;26(8): $756-784$.
20. Network TCGAR. Comprehensive genomic characterization defines human glioblastoma genes and core pathways. Nature. 2008;455(7216): 1061-1068.

21. Hanahan D, Weinberg RA. Hallmarks of cancer: the next generation. Cell. 2011;144(5):646-674.

22. Group BDW. Biomarkers and surrogate endpoints: preferred definitions and conceptual framework. Clin Pharmacol Ther. 2001;69(3):89-95.

23. Sawyers CL. The cancer biomarker problem. Nature. 2008;452(7187): 548-552.

24. Tabatabai G, Stupp R, van den Bent MJ, et al. Molecular diagnostics of gliomas: the clinical perspective. Acta Neuropathol. 2010;120(5): 585-592.

25. Jansen M, Yip S, Louis DN. Molecular pathology in adult gliomas: diagnostic, prognostic, and predictive markers. Lancet Neurol. 2010; 9(7):717-726

26. Hofer S, Lassman AB. Molecular markers in gliomas: impact for the clinician. Target Oncol. 2010;5(3):201-210.

27. Christensen BC, Smith AA, Zheng S, et al. DNA methylation, isocitrate dehydrogenase mutation, and survival in glioma. J Natl Cancer Inst. 2011;103(2):143-153.

28. von Deimling A, Korshunov A, Hartmann C. The next generation of glioma biomarkers: MGMT methylation, BRAF fusions and IDH1 mutations. Brain Pathol. 2011;21(1):74-87.

29. Westermark B. Glioblastoma - a moving target. Ups J Med Sci. 2012; 117(2):251-256.

30. Farias-Eisner G, Bank AM, Hwang BY, et al. Glioblastoma biomarkers from bench to bedside: advances and challenges. Br J Neurosurg. 2012;26(2):189-194.

31. Hegi ME, Diserens AC, Gorlia T, et al. MGMT gene silencing and benefit from temozolomide in glioblastoma. $N \mathrm{Engl} \mathrm{J} \mathrm{Med.}$ 2005;352(10):997-1003.

32. Sathornsumetee S, Reardon DA, Desjardins A, Quinn JA, Vredenburgh JJ, Rich JN. Molecularly targeted therapy for malignant glioma. Cancer. 2007;110(1):13-24

33. Thaker NG, Pollack IF. Molecularly targeted therapies for malignant glioma: rationale for combinatorial strategies. Expert Rev Neurother. 2009;9(12):1815-1836

34. Huang TT, Sarkaria SM, Cloughesy TF, Mischel PS. Targeted therapy for malignant glioma patients: lessons learned and the road ahead. Neurotherapeutics. 2009;6(3):500-512.

35. Polivka J Jr, Polivka J, Rohan V, Topolcan O, Ferda J. New molecularly targeted therapies for glioblastoma multiforme. Anticancer Res. 2012; 32(7):2935-2946.

36. Colman H, Zhang L, Sulman EP, et al. A multigene predictor of outcome in glioblastoma. Neuro Oncol. 2010;12(1):49-57.

37. Saijo N. Critical comments for roles of biomarkers in the diagnosis and treatment of cancer. Cancer Treat Rev. 2012;38(1):63-67.

38. Devilee P, Cleton-Jansen AM, Cornelisse CJ. Ever since Knudson. Trends Genet. 2001;17(10):569-573.

39. Tomlinson IP, Lambros MB, Roylance RR. Loss of heterozygosity analysis: practically and conceptually flawed? Genes Chromosomes Cancer. 2002;34(4):349-353.

40. Beroukhim R, Getz G, Nghiemphu L, et al. Assessing the significance of chromosomal aberrations in cancer: methodology and application to glioma. Proc Natl Acad Sci U S A. 2007;104(50):20007-20012.

41. Mizoguchi M, Kuga D, Guan Y, et al. Loss of heterozygosity analysis in malignant gliomas. Brain Tumor Pathol. 2011;28(3):191-196.

42. Fujisawa H, Kurrer M, Reis RM, Yonekawa Y, Kleihues P, Ohgaki H. Acquisition of the glioblastoma phenotype during astrocytoma progression is associated with loss of heterozygosity on 10q25-qter. Am J Pathol. 1999;155(2):387-394.

43. Fujisawa H, Reis RM, Nakamura M, et al. Loss of heterozygosity on chromosome 10 is more extensive in primary (de novo) than in secondary glioblastomas. Lab Invest. 2000;80(1):65-72.

44. Hata N, Yoshimoto K, Yokoyama N, et al. Allelic losses of chromosome 10 in glioma tissues detected by quantitative single-strand conformation polymorphism analysis. Clin Chem. 2006;52(3):370-378. 
45. Tada K, Shiraishi S, Kamiryo T, et al. Analysis of loss of heterozygosity on chromosome 10 in patients with malignant astrocytic tumors: correlation with patient age and survival. J Neurosurg. 2001;95(4):651-659.

46. Yoshimoto K, Iwaki T, Inamura T, Fukui M, Tahira T, Hayashi K. Multiplexed analysis of post-PCR fluorescence-labeled microsatellite alleles and statistical evaluation of their imbalance in brain tumors. Jpn J Cancer Res. 2002;93(3):284-290.

47. Li J, Yen C, Liaw D, et al. PTEN, a putative protein tyrosine phosphatase gene mutated in human brain, breast, and prostate cancer. Science. 1997; 275(5308):1943-1947.

48. Steck PA, Pershouse MA, Jasser SA, et al. Identification of a candidate tumour suppressor gene, MMAC1, at chromosome 10q23.3 that is mutated in multiple advanced cancers. Nat Genet. 1997;15(4): 356-362.

49. Knobbe CB, Merlo A, Reifenberger G. Pten signaling in gliomas. Neuro Oncol. 2002;4(3):196-211.

50. Endersby R, Baker SJ. PTEN signaling in brain: neuropathology and tumorigenesis. Oncogene. 2008;27(41):5416-5430.

51. Balesaria S, Brock C, Bower M, et al. Loss of chromosome 10 is an independent prognostic factor in high-grade gliomas. $\mathrm{Br} J$ Cancer. 1999;81(8):1371-1377.

52. Kuga D, Mizoguchi M, Guan Y, et al. Prevalence of copy-number neutral $\mathrm{LOH}$ in glioblastomas revealed by genomewide analysis of laser-microdissected tissues. Neuro Oncol. 2008;10(6):995-1003.

53. Ekstrand AJ, James CD, Cavenee WK, Seliger B, Pettersson RF, Collins VP. Genes for epidermal growth factor receptor, transforming growth factor alpha, and epidermal growth factor and their expression in human gliomas in vivo. Cancer Res. 1991;51(8):2164-2172.

54. Wong AJ, Ruppert JM, Bigner SH, et al. Structural alterations of the epidermal growth factor receptor gene in human gliomas. Proc Natl Acad Sci USA. 1992;89(7):2965-2969.

55. Kleihues P, Burger PC, Aldape KD, et al. Glioblastoma. In: Louis DN, Ohgaki H, Wiestler OD, Cavenee WK, editors. The 2007 WHO Classification of Tumours of the Central Nervous System. 4th ed. Lyon, France: IARC press; 2007.

56. Frederick L, Wang XY, Eley G, James CD. Diversity and frequency of epidermal growth factor receptor mutations in human glioblastomas. Cancer Res. 2000;60(5):1383-1387.

57. Pedersen MW, Meltorn M, Damstrup L, Poulsen HS. The type III epidermal growth factor receptor mutation. Biological significance and potential target for anti-cancer therapy. Ann Oncol. 2001;12(6):745-760.

58. Gan HK, Kaye AH, Luwor RB. The EGFRvIII variant in glioblastoma multiforme. J Clin Neurosci. 2009;16(6):748-754.

59. Schlegel J, Merdes A, Stumm G, et al. Amplification of the epidermalgrowth-factor-receptor gene correlates with different growth behaviour in human glioblastoma. Int J Cancer. 1994;56(1):72-77.

60. Shinojima N, Tada K, Shiraishi S, et al. Prognostic value of epidermal growth factor receptor in patients with glioblastoma multiforme. Cancer Res. 2003;63(20):6962-6970.

61. Heimberger AB, Hlatky R, Suki D, et al. Prognostic effect of epidermal growth factor receptor and EGFRvIII in glioblastoma multiforme patients. Clin Cancer Res. 2005;11(4):1462-1466.

62. Nishikawa R, Ji XD, Harmon RC, et al. A mutant epidermal growth factor receptor common in human glioma confers enhanced tumorigenicity. Proc Natl Acad Sci U S A. 1994;91(16):7727-7731.

63. Nagane M, Coufal F, Lin H, Bogler O, Cavenee WK, Huang HJ. A common mutant epidermal growth factor receptor confers enhanced tumorigenicity on human glioblastoma cells by increasing proliferation and reducing apoptosis. Cancer Res. 1996;56(21):5079-5086.

64. Holland EC, Hively WP, DePinho RA, Varmus HE. A constitutively active epidermal growth factor receptor cooperates with disruption of G1 cell-cycle arrest pathways to induce glioma-like lesions in mice. Genes Dev. 1998;12(23):3675-3685.

65. Bachoo RM, Maher EA, Ligon KL, et al. Epidermal growth factor receptor and Ink4a/Arf: convergent mechanisms governing terminal differentiation and transformation along the neural stem cell to astrocyte axis. Cancer Cell. 2002;1(3):269-277.
66. Huang HS, Nagane M, Klingbeil CK, et al. The enhanced tumorigenic activity of a mutant epidermal growth factor receptor common in human cancers is mediated by threshold levels of constitutive tyrosine phosphorylation and unattenuated signaling. J Biol Chem. 1997;272(5): 2927-2935.

67. Huang PH, Mukasa A, Bonavia R, et al. Quantitative analysis of EGFRvIII cellular signaling networks reveals a combinatorial therapeutic strategy for glioblastoma. Proc Natl Acad Sci U S A. 2007;104(31):12867-12872.

68. Prigent SA, Nagane M, Lin H, et al. Enhanced tumorigenic behavior of glioblastoma cells expressing a truncated epidermal growth factor receptor is mediated through the Ras-Shc-Grb2 pathway. J Biol Chem. 1996;271(41):25639-25645.

69. Bonavia R, Inda MM, Vandenberg $\mathrm{S}$, et al. EGFRvIII promotes glioma angiogenesis and growth through the NF-kappaB, interleukin-8 pathway. Oncogene. Epub December 5, 2011.

70. Tanaka K, Babic I, Nathanson D, et al. Oncogenic EGFR signaling activates an mTORC2-NF-kappaB pathway that promotes chemotherapy resistance. Cancer Discov. 2011;1(6):524-538.

71. Mellinghoff IK, Wang MY, Vivanco I, et al. Molecular determinants of the response of glioblastomas to EGFR kinase inhibitors. $N \mathrm{Engl}$ J Med. 2005;353(19):2012-2024.

72. Montano N, Cenci T, Martini M, et al. Expression of EGFRvIII in glioblastoma: prognostic significance revisited. Neoplasia. 2011;13(12): 1113-1121.

73. Bredel M, Scholtens DM, Yadav AK, et al. NFKBIA deletion in glioblastomas. $N$ Engl J Med. 2011;364(7):627-637.

74. Li G, Wong AJ. EGF receptor variant III as a target antigen for tumor immunotherapy. Expert Rev Vaccines. 2008;7(7):977-985.

75. Choi BD, Archer GE, Mitchell DA, et al. EGFRvIII-targeted vaccination therapy of malignant glioma. Brain Pathol. 2009;19(4):713-723.

76. Sampson JH, Heimberger AB, Archer GE, et al. Immunologic escape after prolonged progression-free survival with epidermal growth factor receptor variant III peptide vaccination in patients with newly diagnosed glioblastoma. J Clin Oncol. 2010;28(31):4722-4729.

77. Brandes AA, Franceschi E, Tosoni A, Hegi ME, Stupp R. Epidermal growth factor receptor inhibitors in neuro-oncology: hopes and disappointments. Clin Cancer Res. 2008;14(4):957-960.

78. Lee JC, Vivanco I, Beroukhim R, et al. Epidermal growth factor receptor activation in glioblastoma through novel missense mutations in the extracellular domain. PLoS Med. 2006;3(12):e485.

79. Cho J, Pastorino S, Zeng Q, et al. Glioblastoma-derived epidermal growth factor receptor carboxyl-terminal deletion mutants are transforming and are sensitive to EGFR-directed therapies. Cancer Res. 2011;71(24):7587-7596.

80. Vivanco I, Robins HI, Rohle D, et al. Differential sensitivity of gliomaversus lung cancer-specific EGFR mutations to EGFR kinase inhibitors. Cancer Discov. 2012;2(5):458-471.

81. Vivanco I, Sawyers CL. The phosphatidylinositol 3-kinase AKT pathway in human cancer. Nat Rev Cancer. 2002;2(7):489-501.

82. Choe G, Horvath S, Cloughesy TF, et al. Analysis of the phosphatidylinositol 3'-kinase signaling pathway in glioblastoma patients in vivo. Cancer Res. 2003;63(11):2742-2746.

83. Engelman JA. Targeting PI3K signalling in cancer: opportunities, challenges and limitations. Nat Rev Cancer. 2009;9(8):550-562.

84. Liu P, Cheng H, Roberts TM, Zhao JJ. Targeting the phosphoinositide 3-kinase pathway in cancer. Nat Rev Drug Discov. 2009;8(8):627-644.

85. Mizoguchi M, Nutt CL, Mohapatra G, Louis DN. Genetic alterations of phosphoinositide 3-kinase subunit genes in human glioblastomas. Brain Pathol. 2004;14(4):372-377.

86. Bleeker FE, Lamba S, Zanon C, et al. Absence of AKT1 mutations in glioblastoma. PLoS One. 2009;4(5):e5638.

87. Koul D. PTEN signaling pathways in glioblastoma. Cancer Biol Ther. 2008;7(9):1321-1325

88. Vivanco I, Rohle D, Versele M, et al. The phosphatase and tensin homolog regulates epidermal growth factor receptor (EGFR) inhibitor response by targeting EGFR for degradation. Proc Natl Acad Sci USA. 2010;107(14):6459-6464. 
89. Lian Z, Di Cristofano A. Class reunion: PTEN joins the nuclear crew. Oncogene. 2005;24(50):7394-7400.

90. Shen WH, Balajee AS, Wang J, et al. Essential role for nuclear PTEN in maintaining chromosomal integrity. Cell. 2007;128(1):157-170.

91. Li L, Dutra A, Pak E, et al. EGFRvIII expression and PTEN loss synergistically induce chromosomal instability and glial tumors. Neuro Oncol. 2009;11(1):9-21.

92. McEllin B, Camacho CV, Mukherjee B, et al. PTEN loss compromises homologous recombination repair in astrocytes: implications for glioblastoma therapy with temozolomide or poly(ADP-ribose) polymerase inhibitors. Cancer Res. 2010;70(13):5457-5464.

93. Akhavan D, Cloughesy TF, Mischel PS. mTOR signaling in glioblastoma: lessons learned from bench to bedside. Neuro Oncol. 2010;12(8):882-889.

94. Zoncu R, Efeyan A, Sabatini DM. mTOR: from growth signal integration to cancer, diabetes and ageing. Nat Rev Mol Cell Biol. 2011;12(1): 21-35.

95. Cloughesy TF, Yoshimoto K, Nghiemphu P, et al. Antitumor activity of rapamycin in a Phase I trial for patients with recurrent PTEN-deficient glioblastoma. PLoS Med. 2008;5(1):e8.

96. Vousden $\mathrm{KH}$, Prives $\mathrm{C}$. Blinded by the light: the growing complexity of p53. Cell. 2009;137(3):413-431.

97. Junttila MR, Evan GI. p53 - a Jack of all trades but master of none. Nat Rev Cancer. 2009;9(11):821-829.

98. Ohgaki H, Dessen P, Jourde B, et al. Genetic pathways to glioblastoma: a population-based study. Cancer Res. 2004;64(19):6892-6899.

99. Reifenberger G, Liu L, Ichimura K, Schmidt EE, Collins VP. Amplification and overexpression of the MDM2 gene in a subset of human malignant gliomas without p53 mutations. Cancer Res. 1993; 53(12):2736-2739

100. Batchelor TT, Betensky RA, Esposito JM, et al. Age-dependent prognostic effects of genetic alterations in glioblastoma. Clin Cancer Res. 2004;10(1 Pt 1):228-233.

101. Brown CJ, Lain S, Verma CS, Fersht AR, Lane DP. Awakening guardian angels: drugging the p53 pathway. Nat Rev Cancer. 2009; 9(12):862-873

102. Brown CJ, Cheok CF, Verma CS, Lane DP. Reactivation of $\mathrm{p} 53$ : from peptides to small molecules. Trends Pharmacol Sci. 2011;32(1): $53-62$.

103. Nakamura M, Yonekawa Y, Kleihues P, Ohgaki H. Promoter hypermethylation of the RB1 gene in glioblastomas. Lab Invest. 2001; 81(1):77-82.

104. Puduvalli VK, Kyritsis AP, Hess KR, et al. Patterns of expression of $\mathrm{Rb}$ and $\mathrm{p} 16$ in astrocytic gliomas, and correlation with survival. Int $J$ Oncol. 2000;17(5):963-969.

105. Parsons DW, Jones S, Zhang X, et al. An integrated genomic analysis of human glioblastoma multiforme. Science. 2008;321(5897): $1807-1812$.

106. Yan H, Parsons DW, Jin G, et al. IDH1 and IDH2 mutations in gliomas. N Engl J Med. 2009;360(8):765-773.

107. Ichimura K, Pearson DM, Kocialkowski S, et al. IDH1 mutations are present in the majority of common adult gliomas but rare in primary glioblastomas. Neuro Oncol. 2009;11(4):341-347.

108. Sonoda Y, Kumabe T, Nakamura T, et al. Analysis of IDH1 and IDH2 mutations in Japanese glioma patients. Cancer Sci. 2009;100(10): 1996-1998.

109. Dang L, Jin S, Su SM. IDH mutations in glioma and acute myeloid leukemia. Trends Mol Med. 2010;16(9):387-397.

110. Fu Y, Huang R, Du J, Yang R, An N, Liang A. Glioma-derived mutations in IDH: from mechanism to potential therapy. Biochem Biophys Res Commun. 2010;397(2):127-130.

111. Yen KE, Bittinger MA, Su SM, Fantin VR. Cancer-associated IDH mutations: biomarker and therapeutic opportunities. Oncogene. 2010; 29(49):6409-6417.

112. Dang L, White DW, Gross S, et al. Cancer-associated IDH1 mutations produce 2-hydroxyglutarate. Nature. 2009;462(7274):739-744.
113. Ward PS, Patel J, Wise DR, et al. The common feature of leukemiaassociated IDH1 and IDH2 mutations is a neomorphic enzyme activity converting alpha-ketoglutarate to 2-hydroxyglutarate. Cancer Cell. 2010;17(3):225-234.

114. Jin G, Reitman ZJ, Spasojevic I, et al. 2-hydroxyglutarate production, but not dominant negative function, is conferred by glioma-derived NADP-dependent isocitrate dehydrogenase mutations. PLoS One. 2011;6(2):e16812.

115. Zhao S, Lin $\mathrm{Y}, \mathrm{Xu} \mathrm{W}$, et al. Glioma-derived mutations in IDH1 dominantly inhibit IDH1 catalytic activity and induce HIF-1alpha. Science. 2009;324(5924):261-265.

116. Choi C, Ganji SK, DeBerardinis RJ, et al. 2-hydroxyglutarate detection by magnetic resonance spectroscopy in IDH-mutated patients with gliomas. Nat Med. 2012;18(4):624-629.

117. Figueroa ME, Abdel-Wahab O, Lu C, et al. Leukemic IDH1 and IDH2 mutations result in a hypermethylation phenotype, disrupt TET2 function, and impair hematopoietic differentiation. Cancer Cell.2010; 18(6):553-567.

118. Noushmehr H, Weisenberger DJ, Diefes K, et al. Identification of a $\mathrm{CpG}$ island methylator phenotype that defines a distinct subgroup of glioma. Cancer Cell. 2010;17(5):510-522.

119. Turcan S, Rohle D, GoenkaA, et al. IDH1 mutation is sufficient to establish the glioma hypermethylator phenotype. Nature. 2012;483(7390): $479-483$.

120. Lu C, Ward PS, Kapoor GS, et al. IDH mutation impairs histone demethylation and results in a block to cell differentiation. Nature. 2012;483(7390):474-478.

121. van den Bent MJ, Dubbink HJ, Marie Y, et al. IDH1 and IDH2 mutations are prognostic but not predictive for outcome in anaplastic oligodendroglial tumors: a report of the European Organization for Research and Treatment of Cancer Brain Tumor Group. Clin Cancer Res. 2010; 16(5):1597-1604.

122. Hartmann C, Hentschel B, Wick W, et al. Patients with IDH1 wild type anaplastic astrocytomas exhibit worse prognosis than IDH1-mutated glioblastomas, and IDH1 mutation status accounts for the unfavorable prognostic effect of higher age: implications for classification of gliomas. Acta Neuropathol. 2010;120(6):707-718.

123. Mukasa A, Takayanagi S, Saito K, et al. Significance of IDH mutations varies with tumor histology, grade, and genetics in Japanese glioma patients. Cancer Sci. 2012;103(3):587-592.

124. Jones PA, Baylin SB. The epigenomics of cancer. Cell. 2007;128(4): 683-692.

125. Kelly TK, De Carvalho DD, Jones PA. Epigenetic modifications as therapeutic targets. Nat Biotechnol. 2010;28(10):1069-1078.

126. Rodriguez-Paredes M, Esteller M. Cancer epigenetics reaches mainstream oncology. Nat Med. 2011;17(3):330-339.

127. Nagarajan RP, Costello JF. Molecular epigenetics and genetics in neuro-oncology. Neurotherapeutics. 2009;6(3):436-446.

128. Natsume A, Kondo Y, Ito M, Motomura K, Wakabayashi T, Yoshida J. Epigenetic aberrations and therapeutic implications in gliomas. Cancer Sci. 2010;101(6):1331-1336.

129. Malzkorn B, Wolter M, Riemenschneider MJ, Reifenberger G. Unraveling the glioma epigenome: from molecular mechanisms to novel biomarkers and therapeutic targets. Brain Pathol. 2011;21(6):619-632.

130. Cadieux B, Ching TT, VandenBerg SR, Costello JF. Genome-wide hypomethylation in human glioblastomas associated with specific copy number alteration, methylenetetrahydrofolate reductase allele status, and increased proliferation. Cancer Res. 2006;66(17):8469-8476.

131. Esteller M. Epigenetics in cancer. N Engl J Med. 2008;358(11): 1148-1159.

132. Fanelli M, Caprodossi S, Ricci-Vitiani L, et al. Loss of pericentromeric DNA methylation pattern in human glioblastoma is associated with altered DNA methyltransferases expression and involves the stem cell compartment. Oncogene. 2008;27(3):358-365.

133. Uyeno S, Aoki Y, Nata M, et al. IGF2 but not H19 shows loss of imprinting in human glioma. Cancer Res. 1996;56(23):5356-5359. 
134. Kaina B, Christmann M, Naumann S, Roos WP. MGMT: key node in the battle against genotoxicity, carcinogenicity and apoptosis induced by alkylating agents. DNA Repair (Amst). 2007;6(8):1079-1099.

135. Gerson SL. MGMT: its role in cancer aetiology and cancer therapeutics. Nat Rev Cancer. 2004;4(4):296-307.

136. Silber JR, Bobola MS, BlankA, Chamberlain MC. O(6)-MethylguanineDNA methyltransferase in glioma therapy: Promise and problems. Biochim Biophys Acta. 2012;1826(1):71-82.

137. Costello JF, Futscher BW, Tano K, Graunke DM, Pieper RO. Graded methylation in the promoter and body of the O6-methylguanine DNA methyltransferase (MGMT) gene correlates with MGMT expression in human glioma cells. J Biol Chem. 1994;269(25):17228-17237.

138. Everhard S, Tost J, El Abdalaoui H, et al. Identification of regions correlating MGMT promoter methylation and gene expression in glioblastomas. Neuro Oncol. 2009;11(4):348-356.

139. Minniti G, Salvati M, Arcella A, et al. Correlation between O6-methylguanine-DNA methyltransferase and survival in elderly patients with glioblastoma treated with radiotherapy plus concomitant and adjuvant temozolomide. J Neurooncol. 2011;102(2) 311-316.

140. Gorlia T, van den Bent MJ, Hegi ME, et al. Nomograms for predicting survival of patients with newly diagnosed glioblastoma: prognostic factor analysis of EORTC and NCIC trial 26981-22981/CE.3. Lancet Oncol. 2008;9(1):29-38.

141. Rivera AL, Pelloski CE, Gilbert MR, et al. MGMT promoter methylation is predictive of response to radiotherapy and prognostic in the absence of adjuvant alkylating chemotherapy for glioblastoma. Neuro Oncol. 2010;12(2):116-121.

142. Kreth S, Thon N, Eigenbrod S, et al. O-methylguanine-DNA methyltransferase (MGMT) mRNA expression predicts outcome in malignant glioma independent of MGMT promoter methylation. PLoS One. 2011;6(2):e17156.

143. Weller M, Stupp R, Reifenberger G, et al. MGMT promoter methylation in malignant gliomas: ready for personalized medicine? Nat Rev Neurol. 2010;6(1):39-51.

144. Agnihotri S, Gajadhar AS, Ternamian C, et al. Alkylpurine-DNA-Nglycosylase confers resistance to temozolomide in xenograft models of glioblastoma multiforme and is associated with poor survival in patients. J Clin Invest. 2012;122(1):253-266.

145. Toyota M, Ahuja N, Ohe-Toyota M, Herman JG, Baylin SB, Issa JP. CpG island methylator phenotype in colorectal cancer. Proc Natl Acad Sci U S A. 1999;96(15):8681-8686.

146. Magee JA, Piskounova E, Morrison SJ. Cancer stem cells: impact heterogeneity, and uncertainty. Cancer Cell. 2012;21(3):283-296.

147. Pardal R, Clarke MF, Morrison SJ. Applying the principles of stemcell biology to cancer. Nat Rev Cancer. 2003;3(12):895-902.

148. Rosen JM, Jordan CT. The increasing complexity of the cancer stem cell paradigm. Science. 2009;324(5935):1670-1673.

149. Nguyen LV, Vanner R, Dirks P, Eaves CJ. Cancer stem cells: an evolving concept. Nat Rev Cancer. 2012;12(2):133-143.

150. Galli R, Binda E, Orfanelli U, et al. Isolation and characterization of tumorigenic, stem-like neural precursors from human glioblastoma. Cancer Res. 2004;64(19):7011-7021.

151. Singh SK, Hawkins C, Clarke ID, et al. Identification of human brain tumour initiating cells. Nature. 2004;432(7015):396-401.

152. Sanai N, Alvarez-Buylla A, Berger MS. Neural stem cells and the origin of gliomas. $N$ Engl J Med. 2005;353(8):811-822.

153. Stiles CD, Rowitch DH. Glioma stem cells: a midterm exam. Neuron. 2008;58(6):832-846.

154. Canoll P, Goldman JE. The interface between glial progenitors and gliomas. Acta Neuropathol. 2008;116(5):465-477.

155. Dirks PB. Brain tumor stem cells: bringing order to the chaos of brain cancer. J Clin Oncol. 2008;26(17):2916-2924.

156. Venere M, Fine HA, Dirks PB, Rich JN. Cancer stem cells in gliomas: identifying and understanding the apex cell in cancer's hierarchy. Glia. 2011;59(8):1148-1154.
157. Rahman M, Deleyrolle L, Vedam-Mai V, Azari H, Abd-El-Barr M, Reynolds BA. The cancer stem cell hypothesis: failures and pitfalls. Neurosurgery. 2011;68(2):531-545.

158. Bao S, Wu Q, McLendon RE, et al. Glioma stem cells promote radioresistance by preferential activation of the DNA damage response. Nature. 2006;444(7120):756-760.

159. Eramo A, Ricci-Vitiani L, Zeuner A, et al. Chemotherapy resistance of glioblastoma stem cells. Cell Death Differ. 2006;13(7):1238-1241.

160. Liu G, Yuan X, Zeng Z, et al. Analysis of gene expression and chemoresistance of CD133+ cancer stem cells in glioblastoma. $\mathrm{Mol}$ Cancer. 2006;5:67.

161. Natsume A, Kinjo S, Yuki K, et al. Glioma-initiating cells and molecular pathology: implications for therapy. Brain Tumor Pathol. 2011;28(1):1-12.

162. Fatoo A, Nanaszko MJ, Allen BB, et al. Understanding the role of tumor stem cells in glioblastoma multiforme: a review article. J Neurooncol. 2011;103(3):397-408.

163. Huang Z, Cheng L, Guryanova OA, Wu Q, Bao S. Cancer stem cells in glioblastoma - molecular signaling and therapeutic targeting. Protein Cell. 2010;1(7):638-655.

164. Yoshimoto K, Ma X, Guan Y, et al. Expression of stem cell marker and receptor kinase genes in glioblastoma tissue quantified by real-time RT-PCR. Brain Tumor Pathol. 2011;28(4):291-296.

165. Nicolis SK. Cancer stem cells and "stemness" genes in neuro-oncology. Neurobiol Dis. 2007;25(2):217-229.

166. Dell'Albani P. Stem cell markers in gliomas. Neurochem Res. 2008; 33(12):2407-2415

167. Zeppernick F, Ahmadi R, Campos B, et al. Stem cell marker CD133 affects clinical outcome in glioma patients. Clin Cancer Res. 2008 14(1):123-129.

168. Ma YH, Mentlein R, Knerlich F, Kruse ML, Mehdorn HM, HeldFeindt J. Expression of stem cell markers in human astrocytomas of different WHO grades. J Neurooncol. 2008;86(1):31-45.

169. Strojnik T, Rosland GV, Sakariassen PO, Kavalar R, Lah T. Neural stem cell markers, nestin and musashi proteins, in the progression of human glioma: correlation of nestin with prognosis of patient survival. Surg Neurol. 2007;68(2):133-143; discussion 143-134.

170. Stockhausen MT, Kristoffersen K, Poulsen HS. The functional role of Notch signaling in human gliomas. Neuro Oncol. 2010;12(2) 199-211.

171. Facchino S, Abdouh M, Chatoo W, Bernier G. BMI1 confers radioresistance to normal and cancerous neural stem cells through recruitment of the DNA damage response machinery. J Neurosci. 2010;30(30): 10096-10111.

172. Marie SK, Okamoto OK, Uno M, et al. Maternal embryonic leucine zipper kinase transcript abundance correlates with malignancy grade in human astrocytomas. Int J Cancer. 2008;122(4):807-815.

173. Zhang M, Song T, Yang L, et al. Nestin and CD133: valuable stem cell-specific markers for determining clinical outcome of glioma patients. J Exp Clin Cancer Res. 2008;27:85.

174. Lathia JD, Heddleston JM, Venere M, Rich JN. Deadly teamwork: neural cancer stem cells and the tumor microenvironment. Cell Stem Cell. 2011;8(5):482-485.

175. Beier D, Schulz JB, Beier CP. Chemoresistance of glioblastoma cancer stem cells - much more complex than expected. Mol Cancer. 2011; $10: 128$.

176. Mannino M, Chalmers AJ. Radioresistance of glioma stem cells: intrinsic characteristic or property of the 'microenvironment-stem cell unit'? Mol Oncol. 2011;5(4):374-386

177. Jamal M, Rath BH, Tsang PS, Camphausen K, Tofilon PJ. The brain microenvironment preferentially enhances the radioresistance of CD133(+) glioblastoma stem-like cells. Neoplasia. 2012;14(2): $150-158$.

178. Jamal M, Rath BH, Williams ES, Camphausen K, Tofilon PJ. Microenvironmental regulation of glioblastoma radioresponse. Clin Cancer Res. 2010;16(24):6049-6059. 
179. Fuller GN, Hess KR, Rhee CH, et al. Molecular classification of human diffuse gliomas by multidimensional scaling analysis of gene expression profiles parallels morphology-based classification, correlates with survival, and reveals clinically-relevant novel glioma subsets. Brain Pathol. 2002;12(1):108-116.

180. Freije WA, Castro-Vargas FE, Fang Z, et al. Gene expression profiling of gliomas strongly predicts survival. Cancer Res. 2004;64(18): 6503-6510.

181. Li A, Walling J, Ahn S, et al. Unsupervised analysis of transcriptomic profiles reveals six glioma subtypes. Cancer Res. 2009;69(5): 2091-2099.

182. Ng K, Kim R, Kesari S, Carter B, Chen CC. Genomic profiling of glioblastoma: convergence of fundamental biologic tenets and novel insights. J Neurooncol. 2012;107(1):1-12.

183. Vitucci M, Hayes DN, Miller CR. Gene expression profiling of gliomas: merging genomic and histopathological classification for personalised therapy. Br J Cancer. 2011;104(4):545-553.

184. Sulman EP, Aldape K. The use of global profiling in biomarker development for gliomas. Brain Pathol. 2011;21(1):88-95.

185. Marko NF, Quackenbush J, Weil RJ. Why is there a lack of consensus on molecular subgroups of glioblastoma? Understanding the nature of biological and statistical variability in glioblastoma expression data. PLoS One. 2011;6(7):e20826.

186. Riddick G, Fine HA. Integration and analysis of genome-scale data from gliomas. Nat Rev Neurol. 2011;7(8):439-450.

187. Phillips HS, Kharbanda S, Chen R, et al. Molecular subclasses of high-grade glioma predict prognosis, delineate a pattern of disease progression, and resemble stages in neurogenesis. Cancer Cell. 2006; 9(3):157-173.

188. Verhaak RG, Hoadley KA, Purdom E, et al. Integrated genomic analysis identifies clinically relevant subtypes of glioblastoma characterized by abnormalities in PDGFRA, IDH1, EGFR, and NF1. Cancer Cell. 2010;17(1):98-110.

189. Huse JT, Phillips HS, Brennan CW. Molecular subclassification of diffuse gliomas: seeing order in the chaos. Glia. 2011;59(8): 1190-1199.

190. Carro MS, Lim WK, Alvarez MJ, et al. The transcriptional network for mesenchymal transformation of brain tumours. Nature. 2010; 463(7279):318-325.

191. Bhat KP, Salazar KL, Balasubramaniyan V, et al. The transcriptional coactivator TAZ regulates mesenchymal differentiation in malignant glioma. Genes Dev. 2011;25(24):2594-2609.

192. Prins RM, Soto H, Konkankit V, et al. Gene expression profile correlates with T-cell infiltration and relative survival in glioblastoma patients vaccinated with dendritic cell immunotherapy. Clin Cancer Res. 2011;17(6):1603-1615.

193. Filipowicz W, Bhattacharyya SN, Sonenberg N. Mechanisms of posttranscriptional regulation by microRNAs: are the answers in sight? Nat Rev Genet. 2008;9(2):102-114.

194. Lujambio A, Lowe SW. The microcosmos of cancer. Nature. February 16, 2012;482(7385):347-355.

195. Kasinski AL, Slack FJ. Epigenetics and genetics. MicroRNAs en route to the clinic: progress in validating and targeting microRNAs for cancer therapy. Nat Rev Cancer. 2011;11(12):849-864.
196. Babashah S, Soleimani M. The oncogenic and tumour suppressive roles of microRNAs in cancer and apoptosis. Eur J Cancer. 2011; 47(8):1127-1137.

197. Chen CZ. MicroRNAs as oncogenes and tumor suppressors. $N$ Engl J Med. 2005;353(17):1768-1771.

198. Esquela-Kerscher A, Slack FJ. Oncomirs - microRNAs with a role in cancer. Nat Rev Cancer. 2006;6(4):259-269.

199. Chan JA, Krichevsky AM, Kosik KS. MicroRNA-21 is an antiapoptotic factor in human glioblastoma cells. Cancer Res. 2005;65(14): 6029-6033.

200. Papagiannakopoulos T, Shapiro A, Kosik KS. MicroRNA-21 targets a network of key tumor-suppressive pathways in glioblastoma cells. Cancer Res. 2008;68(19):8164-8172.

201. Malzkorn B, Wolter M, Liesenberg F, et al. Identification and functional characterization of microRNAs involved in the malignant progression of gliomas. Brain Pathol. 2010;20(3):539-550.

202. Pang JC, Kwok WK, Chen Z, Ng HK. Oncogenic role of microRNAs in brain tumors. Acta Neuropathol. 2009;117(6):599-611.

203. Nicoloso MS, Calin GA. MicroRNA involvement in brain tumors: from bench to bedside. Brain Pathol. 2008;18(1):122-129.

204. Lawler S, Chiocca EA. Emerging functions of microRNAs in glioblastoma. J Neurooncol. 2009;92(3):297-306.

205. Mizoguchi M, Guan Y, Yoshimoto K, et al. MicroRNAs in human malignant gliomas. J Oncol. 2012;2012:732874.

206. Guan Y, Mizoguchi M, Yoshimoto K, et al. MiRNA-196 is upregulated in glioblastoma but not in anaplastic astrocytoma and has prognostic significance. Clin Cancer Res. 2010;16(16):4289-4297.

207. Lu J, Getz G, Miska EA, et al. MicroRNA expression profiles classify human cancers. Nature. 2005;435(7043):834-838.

208. Srinivasan S, Patric IR, Somasundaram K. A ten-microRNA expression signature predicts survival in glioblastoma. PLoS One. 2011; 6(3):e17438.

209. Kim TM, Huang W, Park R, Park PJ, Johnson MD. A developmental taxonomy of glioblastoma defined and maintained by MicroRNAs. Cancer Res. 2011;71(9):3387-3399.

210. Kalinina J, Peng J, Ritchie JC, Van Meir EG. Proteomics of gliomas: initial biomarker discovery and evolution of technology. Neuro Oncol. 2011;13(9):926-942.

211. Iwamoto FM, Hottinger AF, Karimi S, et al. Serum YKL-40 is a marker of prognosis and disease status in high-grade gliomas. Neuro Oncol. 2011;13(11):1244-1251.

212. Kosaka N, Iguchi H, Ochiya T. Circulating microRNA in body fluid: a new potential biomarker for cancer diagnosis and prognosis. Cancer Sci. 2010;101(10):2087-2092.

213. Teplyuk NM, Mollenhauer B, Gabriely G, et al. MicroRNAs in cerebrospinal fluid identify glioblastoma and metastatic brain cancers and reflect disease activity. Neuro Oncol. 2012;14(6):689-700.

214. Skog J, Wurdinger T, van Rijn S, et al. Glioblastoma microvesicles transport RNA and proteins that promote tumour growth and provide diagnostic biomarkers. Nat Cell Biol. 2008;10(12):1470-1476.

215. Graner MW, Alzate O, Dechkovskaia AM, et al. Proteomic and immunologic analyses of brain tumor exosomes. FASEB J. 2009;23(5): $1541-1557$.
Current Biomarker Findings

\section{Publish your work in this journal}

Current Biomarker Findings is an international, peer-reviewed, open access journal publishing original research, reports, reviews and commentaries on all areas of biomarker research. The manuscript management system is completely online and includes a very quick and fair
Dovepress

peer-review system. Visit http://www.dovepress.com/testimonials.php to read real quotes from published authors. 